\title{
Erratum to: Introducing core-shell technology for conformance control
}

Francesca Verga ${ }^{1, *}$, Mariangela Lombardi ${ }^{2}$, Giuseppe Maddinelli $^{3}$, and Laura Montanaro ${ }^{2}$

${ }^{1}$ Politecnico di Torino, DIATI - Dipartimento di Ingegneria dell'Ambiente, del Territorio e delle Infrastructure, corso Duca degli Abruzzi 24, 10129 Torino, Italy

${ }^{2}$ Politecnico di Torino, DISAT - Dipartimento di Scienza Applicata e Tecnologia, corso Duca degli Abruzzi 24, 10129 Torino, Italy

${ }^{3}$ Eni SpA, via F. Maritano 26, 20097 S. Donato M., Milano, Italy

Accepted: 29 June 2018

Oil \& Gas Science and Technology - Revue d'IFP Energies nouvelles 72, 5 (2017)

Two of the authors of the article "Introducing Core-Shell Technology for Conformance Control" https://ogst.ifpenergiesnouvelles.fr/articles/ogst/abs/2017/01/ogst160054/ ogst160054.html published open access in the journal Oil \& Gas Science and Technology, found out that there is a wrong affiliation in the article as for their Department name.

Professor Laura Montanaro and Professor Mariangela Lombardi were erroneously affiliated in Department "DIATI - Dipartimento di Ingegneria dell'Ambiente, del Territorio e delle Infrastructure".

The correct affiliation is:

Professor Laura Montanaro and Professor Mariangela Lombardi are both affiliated to the Department
"DISAT - Dipartimento di Scienza Applicata e Tecnologia" of Politecnico di Torino, not to the Department "DIATI - Dipartimento di Ingegneria dell'Ambiente, del Territorio e delle Infrastructure" as written in the online version article, while for the authors Montanaro and Lombardi it should be DISAT.

DIATI is the correct affiliation only for Professor Francesca Verga.

\footnotetext{
* Corresponding author: francesca.verga@polito.it
} 